Revista de Economia Política, vol. 33, n 2 (131), pp. 360-366, abril-junho/2013

\title{
Ignacy Sachs e a nave espacial Terra
}

\section{LUIZ CARLOS BRESSER-PEREIRA*}

This paper is a short survey of the work of Ignacy Sachs - one of the pioneers of structuralist development economics and an outstanding economist dedicated to environmental economics. Sachs is Polish and a disciple of Michael Kalecki, but he is also a Brazilian and a French, given his strong ties with these two countries. He knows the importance of markets in the coordination of the economy, but, as a developmental economist, he attributes a key role to economic planning. Only through the deliberate action of the state it will be possible to achieve economic growth, reduction of inequalities, and protection of the environments - only through deliberate action way men and women will be able to conduct the Spaceship Earth to economic, social and environmental development and assure a decent work to all.

Keywords: economic development; environment; decent work; patterns of growth.

JEL Classification:_O10; O20.

O século XX foi o século da ciência e, por isso, foi marcado por significativos avanços econômicos. Seu preço, porém, foi grande, porque levou os cientistas sociais - principalmente os economistas - a uma tentativa de separação radical entre a ciência e a moral em nome de uma arrogante visão de seu tema de estudo. Uma coisa é o mundo do ser, outro, o do dever ser, mas se essa distinção for realizada de maneira linear ao invés de dialética, o resultado será ou uma crença excessiva na ciência e a atribuição de papel secundário às questões morais, ou a adoção de uma postura normativa racional e moralista. Ignacy Sachs é e sempre foi um economista, mas jamais padeceu do primeiro mal, tão frequente entre eles. Pelo contrário, ainda que soubesse bem a diferença entre os dois campos, não se deixou levar pelo belo canto da ciência. Para ele uma ciência social só é legítima se for referida a valores. "Nada de parar o crescimento enquanto houver pobres e desigualdades sociais gritantes; mas é imperativo que esse crescimento mude no que se refere a suas modali-

\footnotetext{
* Professor emérito da Fundação Getulio Vargas. E-mail: bresserpereira@gmail.com.
} 
dades e, sobretudo, à divisão de seus frutos. Precisamos de outro crescimento para um outro desenvolvimento" (2009a: 232).

Ignacy Sachs é hoje o principal economista mundial do eco-desenvolvimento. É o economista que, conjuntamente com Maurice Strong e Marc Nerfin, ajudou a redigir a declaração final da Conferência das Nações Unidas de Estocolmo, de 1972, a partir da qual a proteção do ambiente se transformou em um problema e um objetivo mundial. Antes disso, porém, ele é um dos pioneiros da teoria econômica estruturalista do desenvolvimento (development economics) - uma teoria econômica desenvolvimentista que teve seu auge nos anos 1950, entrou em crise a partir de meados dos anos 1970 - quando a teoria econômica dominante se torna neoclássica e neoliberal - mas está reemergindo nos anos 2000 com o nome de macroeconomia estruturalista do desenvolvimento. Outra forma de definir Ignacy Sachs é dizer que é um grande intelectual que rejeita a torre de marfim da universidade — da École des Hautes Études en Sciences Sociales, onde ele ensina - e está sempre e vigorosamente mergulhado na prática. Nessa prática, ele está sempre na defesa de seus ideais de liberdade, justiça social e defesa do meio ambiente; sempre utópico portanto, mas, também, sempre pragmático; sempre envolvido em definir e participar de projetos de interesse econômico, social e ambiental viáveis que fortaleçam os pobres, principalmente os camponeses, ou então encaminhem a solução dos grandes problemas globais como o do efeito estufa. Não aceitou as ofertas de cargos que recebeu dentro do sistema das Nações Unidas, mas adotou o conselho de seu mestre, Michael Kalecki, quando saiu da Polônia pela segunda vez: "Se puder, seja consultor. É absolutamente necessário adquirir uma experiência prática”.

No plano do método científico adota uma perspectiva histórica, rejeita os modelos hipotético-dedutivos da teoria neoclássica, e pensa pragmaticamente. Para ele não existe ciência social pura: "Quando nós deixamos de lado os modelos de teoria pura e nos voltamos para os mecanismos de ação mais 'realistas' de um sistema econômico particular em um quadro dado de circunstância, o uso de modelos se torna efetivo, e, na nossa opinião, recomendável" (Sachs, 1963: 21). Para ele a economia é teoria e é também forma de pensar associada à prática. Conforme nos diz, "as ciências sociais têm essencialmente um valor heurístico [de nos ajudar a pensar]. Ajudam a fazer as perguntas certas, cuja pertinência e articulação não são nada evidentes e que não viriam ao espírito de um observador pouco experiente. Mas as respostas a essas perguntas só podem vir da práxis” (2009a: 323).

Ignacy Sachs possui tripla nacionalidade: ele é polonês, brasileiro e francês; e é quase indiano porque fez seu doutorado em economia na School of Economics de Delhi. É polonês porque nasceu na Polônia, fugiu do nazismo com seus pais do nazismo em 1939, e voltou à Polônia depois da Segunda Guerra Mundial. Brasileiro, porque acabou chegando ao Brasil em 1941, com 13 anos, e aqui fez seu curso de graduação em economia, e porque transformou o Brasil e seu governo, independente do partido que esteja no poder, no principal objeto de seus conselhos e trabalhos. Em 1954 retornou à Polônia para trabalhar no governo e fazer seu doutorado, mas este ele realizou na Índia onde atuou como segundo secretário da embaixada polonesa durante três anos, entre 1957 e 1960. Conheceu Michael Kalecki — o fundador da macroeconomia ao lado de John Maynard Keynes, e um dos economistas associados às Nações Unidas que, no após Segunda Guerra Mundial, criaram a teoria 
econômica do desenvolvimento - na sua primeira estada em Varsóvia, tornou-se amigo dele na Índia, e, de volta à Polônia, tornou-se um de seus principais assessores, dirigindo o novo Centro de Economias em Desenvolvimento. Em 1968, quando o antissemitismo voltara a tomar conta do seu país de nascença, Sachs novamente foi para o exílio, agora na França, onde logo se tornou professor da EHESS e fundou o Centro de Estudos sobre o Brasil Contemporâneo.

Ignacy Sachs faz parte da segunda geração dos economistas da teoria clássica ou estruturalista do desenvolvimento. A primeira foi a de Rosenstein-Rodan, Hans Singer, Gunnar Myrdal, Michael Kalecki e Raul Prebisch; a segunda de Celso Furtado, Albert Hirschman, Hollis Chenery e dele próprio. O privilégio de ter tido Michael Kalecki como inspirador de sua tese sobre a Índia é algo que Ignacy jamais deixa de sublinhar. Dessa forma, expressa uma velha verdade: o reconhecimento dos mestres é um sinal de grandeza dos discípulos. Sua tese de doutorado, Capitalismo de Estado e Subdesenvolvimento (1964) é um clássico da teoria do desenvolvimento. Nesse livro Sachs verifica que depois da Segunda Guerra Mundial o Estado havia aumentado sua participação na economia, e o modelo desenvolvimentista se tornara dominante tanto nos países ricos como nos países em desenvolvimento. Entre estes, que são seu tema, ele vê dois padrões de desenvolvimento. $\mathrm{O}$ modelo japonês envolve uma ampla associação entre a burocracia pública e a classe capitalista: "o setor público deve ter um lugar permanente apenas para cobrir as despesas sociais no campo dos serviços públicos, provendo finanças para as empresas privadas...; (b) o Estado poderá começar novas aventuras industriais, mas prevê-se sua privatização... (c) o Estado facilita a formação de grupos monopolistas". Já o padrão indiano "prima por assegurar a primazia do Estado em setores básicos da indústria, enfraquecendo a concentração de capital privado - o que supõe um sistema abrangente de planejamento" (Sachs 1964: 95 e 202). Quanto ao Brasil, Sachs prevê a preponderância do modelo japonês. Afinal, sabemos hoje que foi o modelo japonês que prevaleceu não apenas no Brasil, mas em todos os países de desenvolvimento retardatário que realizam o catching up ou alcançamento - um modelo desenvolvimentista no qual o Estado controla e principalmente a planeja uma parte importante do setor monopolista da economia, mas privatiza o setor competitivo deixando sua coordenação por conta do mercado, e pratica uma política econômica ativa.

Economista, ele jamais perde de vista os aspectos éticos do desenvolvimento. Em A Terceira Margem (2009: 347), seu livro de memórias, ele defende um desenvolvimento includente que envolva o crescimento econômico, a diminuição das desigualdades e a proteção do ambiente. E dá especial importância ao problema do trabalho. Não apenas ao problema do emprego, mas também o do trabalho decente - "um trabalho convenientemente remunerado, levando-se em conta o nível de desenvolvimento do país, que se faz em condições de salubridade também aceitáveis e dá lugar a relações humanas que respeitam a dignidade do trabalhador".

Ele é dotado de uma visão ampla e de um espírito crítico forte. Para ele a humanidade enfrenta hoje um impasse profundo. Para Sachs (2009b: 6), estamos sentados sobre as ruínas de quatro paradigmas: "Com a invasão da Tchecoslováquia em 1968 e o esmagamento de seu projeto de socialismo com rosto humano, o socialismo real começou sua agonia. A queda do muro de Berlim em 1989 anunciou seu enterro. A descida aos infernos da Argentina marcou o fracasso do paradigma neo- 
liberal conhecido pelo nome de Consenso de Washington. Que dizer do crescimento econômico aprofundando as desigualdades? Foi o caso do 'milagre brasileiro' na época dos generais e hoje é a China... Resta o paradigma social-democrata, que entrou em crise ao renunciar a suas origens socialistas. A aceitação incondicional da economia de mercado é incompatível com a intenção exibida de recusa da sociedade de mercado".

Em seu paper mais recente sobre teoria do desenvolvimento econômico, "Revisiting development in the twenty-first century" (2009b), ele faz uma análise ampla da teoria econômica do desenvolvimento, de como ela prosperou nos 30 Anos Dourados do Capitalismo (1945-1975), e como entrou em crise nos 30 anos sombrios que se seguiram, os 30 Anos Neoliberais do Capitalismo. Analisa também a crise dos regimes que pretenderam implantar o socialismo mas falharam. Falharam "porque demonstraram não ser uma alternativa viável aos padrões de consumo e ao estilo de vida ocidental", mas o principal problema foi político: afinal a União Soviética foi um regime autoritário que se impôs de forma imperialista na Europa Oriental. Existe, entretanto, uma alternativa para o capitalismo liberal: as "economias mistas" que, segundo ele nos informa, foram discutidas nos anos 1950, e publicadas mais tarde por seu mestre Michael Kalecki (1970), e por Shigeto Tsuru (1993). Em suas palavras, "O fracasso do socialismo real e os impasses da teologia neoliberal de mercado indicam que o sistema institucional dominante será o das economias mistas com um setor de mercado forte mas regulado, e com uma presença significativa do Estado desenvolvimentista" (2009b: 14).

Cada vez que o encontro, ele tem novas histórias a contar. Algumas se referem a seus projetos em defesa dos pequenos: como, por exemplo, quando assessorou o Sebrae a desenvolver um projeto de produção do dendê em unidades familiares combinadas com usinas empresariais de processamento. Outras vezes, ele está dando assessoria ao governo brasileiro, ou às Nações Unidas, sobre o desenvolvimento includente e autossustentável, ou sobre o aproveitamento da biomassa para a produção de energia autorrenovável. Em um trabalho escrito para a UNCTAD das Nações Unidas, "The biofuels controversy" (2007), ele não vê conflito entre a segurança energética e a alimentar desde que a produção de biomassa para a energia seja bem regulada pelo Estado, tendo como critérios não apenas custo, mas também interesse social e proteção ambiental. Em um trabalho mais recente, La Main Visible (2011a: 9), cujo subtítulo é "Ter êxito na entrada no antropoceno", Sachs nos oferece uma grande visão da história da humanidade para discutir seu problema ambiental atual. Brincando com Molière ele nos diz que "da mesma forma que Monsieur Jourdain, em Le Bourgeois Gentilhomme, fazia prosa sem o saber, nós entramos em uma nova era geológica, o antropoceno, já há algum tempo e não nos apercebemos disto. $\mathrm{Na}$ verdade, com três séculos de atraso, já que a entrada no antropoceno data da Revolução Industrial”.

Para Sachs duas grandes revoluções marcaram a humanidade: a Revolução Neolítica e a Revolução Industrial. A primeira revolução se estendeu do ano 9.000 ao ano 3.000 antes de Cristo, e foi marcada pela invenção da agricultura, pela domesticação de animais, pela transição das tribos errantes para as sociedades sedentárias, a pedra polida, a cerâmica, a metalurgia, o começo da urbanização, e o surgimento dos primeiros impérios ou das primeiras civilizações. É a passagem da pré-história 
para a história. Vivemos hoje no antropoceno porque, afinal, o homem apenas se tornou relativamente senhor da sua história a partir da Revolução Capitalista que, em cada país, é constituída pela respectiva revolução nacional e a revolução industrial. Antes as grandes civilizações correspondiam a impérios e nasciam e morriam juntamente com eles. Desde a revolução capitalista isto não mais acontece. Impérios modernos como os da Grã-Bretanha e da França podem ter entrado em decadência, mas a sociedade capitalista ou a civilização moderna continua forte, e, o que é mais importante, todos os países gradualmente aderem à ela, como, nos últimos 30 anos vimos acontecer de forma dramática com a China.

Sachs usa o conceito de antropoceno - um período da vida social no qual, como Marx salientava, o ser humano passa a ocupar o seu centro - para pensar a sociedade mundial atual como um todo e sua sobrevivência. Ele pensa no mundo como uma nave espacial que os homens e mulheres estão conduzindo. Como-, através das revoluções tecnológicas e do planejamento. Para onde? Sua preocupação fundamental é a de "assegurar aos 9 bilhões de humanos que viverão sobre a terra em 2050 uma vida digna de ser vivida sem deixar cair a nave espacial Terra" (2011a: 12). Para lograr esse objetivo - para organizar nosso futuro - cinco tarefas são cruciais para ele: o planejamento, a revolução energética, a revolução verde, a revolução azul, e a cooperação internacional.

Como desenvolvimentista que sempre foi, Ignacy Sachs acredita e defende o planejamento, mas de forma moderada. Lembra que este precisa envolver empresários, trabalhadores, a sociedade civil organizada, e o Estado. E não se trata de planificar toda a economia, mas os setores que não são competitivos e, portanto, que o mercado não tem condições de bem coordenar. O planejamento deve começar pelo nível local, e pela identificação, nesse nível, dos pontos de estrangulamento. Em seguida será necessário articular esses planos no nível regional e nacional. Algo que é preciso fazer gradual e permanentemente. É através do planejamento e da administração diária que afinal os homens realizam seus objetivos de bem-estar, segurança, liberdade, justiça, e proteção do ambiente.

Em relação à revolução energética, Sachs aposta nas energias renováveis, e lembra que a energia nuclear é a aposta do Dr. Fausto - no que ele tem razão, como os acidentes nucleares têm demonstrado. Em relação à revolução verde, não é a revolução verde "aristocrática, dispendiosa de recursos, mas a revolução do 'evergreen' que está sendo desenvolvida principalmente na Índia. Quanto à revolução azul, ele aposta na piscicultura e na produção intensiva envolvendo piscicultura, horticultura e arboricultura.

Finalmente, Sachs dá ênfase à cooperação internacional na solução dos grandes problemas ambientais do nosso tempo. Ele sabe o quanto é difícil essa cooperação em um sistema de estados-nação com níveis muito desiguais de crescimento, todos competindo no quadro da globalização. E afirma, fiel à sua visão ao mesmo tempo moral do mundo: "idealmente nós deveríamos nos dedicar a diminuir a taxa de crescimento daqueles que têm uma pegada ecológica bem superior à média mundial, de maneira a permitir àqueles que estão ainda abaixo desse nível de aproveitar sua biocapacidade". Mas ele é um notável economista que não perde o sentido da realidade, e imediatamente acrescenta: "Mas aí as coisas se complicam. Se as economias do principais 
países ricos começam a decrescer, será extremamente difícil fazer progredir a produção material dos países que não pertencem ao clube dos ricos” (2011: 27).

Ignacy Sachs sempre foi um crítico severo tanto do neoliberalismo quanto dos ambientalistas defensores do crescimento zero. Nas suas palavras (Sachs 1986: 28), “os 'zeristas' (partidários da taxa de crescimento zero) ficaram presos a uma falsa alternativa. Além disso, confundiram dois problemas muito diferentes: a taxa de crescimento (a taxa zero não tendo por si só nenhuma virtude estabilizadora) e a taxa de exploração da natureza. Mais recentemente, ele critica a ideia que hoje se expande na Europa do "decrescimento" - uma retomada das ideias de crescimento zero do início dos anos 1970 - que agora ao invés de acentuar o esgotamento dos recursos naturais, reflete o pessimismo dos europeus em relação ao futuro. O crescimento continuará necessário, lembra Ignacy, enquanto se tratar de dar condições razoáveis de vida para todos: "nós não temos o direito de nos paralisar enquanto não houvermos alcançado um nível decente de consumo material”. Mas para isso é preciso lembrar de Gandhi, para quem o desenvolvimento visava atender as necessidades, não a cupidez. E acrescenta que é preciso lembrar o Padre Lebret que já nos anos 1950 afirmava que "o futuro pertence a uma civilização do ser na repartição equitativa do haver" ${ }^{6}$

Para Ignacy Sachs, uma estratégia de desenvolvimento sócio- econômico a longo prazo e ecologicamente consciente deve aspirar à minimização das retiradas sobre os estoques de recursos não renováveis, afinal de contas limitados, procurando não pôr em perigo os equilíbrios térmicos do planeta pelo uso excessivo da energia fóssil e nuclear. No entanto, ela pode e deve tirar o máximo proveito do fluxo de energia solar e de recursos renováveis obtidos através da bioconversão desta energia, atentando sempre para o desencadeamento normal dos ciclos ecológicos, que precisamente asseguram a renovação desses recursos". Para ele o que se deve buscar são soluções triganhadoras, combinando crescimento, proteção do ambiente, e diminuição das desigualdades. Sachs sempre foi e continua sendo um desenvolvimentista, mas está sempre renovando e atualizando seu pensamento. Por isso não apenas suas ideias mas também sua experiência, sua competência técnica e sua sabedoria têm sido tão valiosas para o Brasil.

Os três grandes desafios que o mundo enfrenta são o desenvolvimento econômico, a igualdade razoável e a sustentabilidade ecológica. Trata-se de promover o desenvolvimento econômico e de fazê-lo de forma a diminuir ao invés de aumentar a desigualdade, assegurando-se que esse desenvolvimento seja sustentável do ponto de vista ambiental. O desenvolvimento econômico é fundamental para os seis bilhões de habitantes dos países ricos e dos países de renda média, como o Brasil, a Índia ou a China. Nesses países ainda há muita pobreza, mas eles têm recursos humanos e de capital para promover seu próprio desenvolvimento econômico. Se contarem com elites e governos identificados com o interesse nacional, os países de renda média poderão, como já está acontecendo principalmente em relação aos países asiáticos dinâmicos, convergir para os níveis de renda dos países ricos. Já para os países pobres, onde vivem

\footnotetext{
${ }^{6}$ Louis-Joseph Lebret (1897-1966) foi um dominicano francês que fundou a revista Economie et Humanisme. Seu trabalho e a instituição Economia e Humanismo tiveram repercussão no Brasil, onde o principal representante foi Francisco Whitaker Ferreira.
} 
um bilhão de pessoas, não há soluções à vista. Nos dois casos, porém, está claro para Ignacy Sachs que é preciso reinventar o Estado desenvolvimentista, que pode e deve assumir muitas formas, "mas uma coisa é certa: apesar do mantra neoliberal que proclama o declínio dos Estados, a responsabilidade assumida pelos Estados desenvolvimentistas aumentou" (2009b: 15). E enumera, em seguida, as cinco áreas em que o Estado desenvolvimentista deverá atuar: (1) articulação, de um lado, com o nível regional e local e, de outro, com o transnacional, na qual "o ponto nevrálgico é a interface entre as nações frágeis e a economia global"; (2) harmonização do social e do ambiental com o desenvolvimento econômico, buscando "soluções triganhadoras"; (3) promoção de associações entre empresas, trabalhadores, o Estado e a sociedade civil; (4) constituição de formas novas e flexíveis de planejamento; e (5) patrocínio de pesquisas públicas sobre temas selecionados relativos ao uso de tecnologia trabalho-intensiva, de tecnologia poupadora de água e de terra, de mitigação do aquecimento global a novos paradigmas de geração de energia, e, principalmente, de políticas "que assegurem oportunidades de trabalho decente para todos.

Ignacy Sachs não pretendia escrever uma autobiografia. A Terceira Margem originou-se de uma série de entrevistas, que duraram quase um ano, feitas a Thierry Paquot. Mas este, ao final, impressionado com a coerência das respostas e a grandeza do personagem, preferiu retirar suas perguntas, e deixar o belo texto correr em nome do entrevistado, limitando-se a escrever o prefácio. Também ele se deixou encantar por essa grande figura humana e intelectual que é Ignacy Sachs. Um economista e um humanista - um Don Quixote sempre em busca de seus ideais, mas sem perder o espírito realista e pragmático de Sancho Pança; um homem orientado por valores, fiel a seus princípios, mas com capacidade de apresentar soluções viáveis para os problemas que enfrenta. A nave espacial Terra pode ser conduzida de muitas maneiras, com muitos instrumentos, e em todos os níveis da sociedade. Tanto ao nível das ideias e da política quanto das organizações, da vida comunitária, e da ação individual. Sachs valoriza essas ações de construção social desde que elas estejam voltadas para um futuro em que o trabalho seja decente e a dignidade humana, respeitada.

\section{REFERÊNCIAS BIBLIOGRÁFICAS}

KALECKI, Michael (1970 [1993]) "Problems of financing economic development in a mixed economy”. In Collected Works of Michal Kalecki, vol. 5: Developing Economies (Jerzy Osiatyñski, org.). Oxford: Clarendon Press, 1993: 145-169.

SACHS, Ignacy (1963 [1965]) Foreign Trade and Economic Development of Underdeveloped Countries. Londres: Asia Publishing House. Publicação original em polonês, 1963.

SACHS, Ignacy (1964 [1969]) Capitalismo de Estado e Subdesenvolvimento. Petrópolis: Editora Vozes. Publicação original em inglês, 1964.

SACHS, Ignacy (1985) Ecodesenvolvimento: Crescer sem Destruir, São Paulo: Editora Vértice.

SACHS, Ignacy (2007) “The biofuels controversy”. Genebra: UNCTAD, novembro 2007.

SACHS, Ignacy (2009a) A Terceira Margem. São Paulo: Companhia das Letras.

SACHS, Ignacy (2009b) "Revisiting development in the twenty-first century", International Journal of Political Economy, 38 (3) outono 2009: 5-21.

SACHS, Ignacy (2011a) La Main Visible. Angers: Groupe ESA.

SACHS, Ignacy (2011b) “Entering the anthropocene: 'Geonauts' or sorcerer's apprentices?” Social Science Information (Sage) 2011: 462-471.

TSURU, Shigeto (1993) Institutional Economics Revisited. Cambridge: Cambridge University Press. 